\title{
Selenium in Soil-Crop-Animal System: A Holistic Perspective to Manage Animal and Human Health
}

\author{
Uttam Saha $^{1}$, Abioye Fayiga ${ }^{2,}$, , Bipul K. Biswas ${ }^{3}$, Leticia Sonon ${ }^{1}$ \\ ${ }^{1}$ Agricultural and Environmental Services Laboratories, University of Georgia Cooperative Extension, Athens, USA \\ ${ }^{2}$ Independent Scholar, Ibadan, Nigeria \\ ${ }^{3}$ Department of Biotechnology, Fort Valley State University, Fort Valley, USA
}

Email address:

abioyeg@aol.com (A. Fayiga)

${ }^{*}$ Corresponding author

\section{To cite this article:}

Uttam Saha, Abioye Fayiga, Bipul K. Biswas, Leticia Sonon. Selenium In Soil-Crop-Animal System: A Holistic Perspective to Manage Animal and Human Health. International Journal of Applied Agricultural Sciences. Vol. 3, No. 3, 2017, pp. 51-66.

doi: $10.11648 /$ j.ijaas.20170303.11

Received: March 10, 2017; Accepted: March 24, 2017; Published: April 25, 2017

\begin{abstract}
Selenium (Se) dependent enzymes play important roles in physiological functions such as thyroid hormone metabolism, strengthens anti-oxidant defense system and immune system. However, about 800 million people worldwide are believed to be deficient in Se which is attributed to low Se levels in the soil. This is because Se in plant and animal products in human diet depends upon the available Se in the soil. Deficiency of Se can be prevented or treated by adequate dietary intake or through direct supplementation. There have been reports that patients with dilated cardiomyopathy, HIV viral loads and cancer have responded to Se supplementation. However, food fortification has been found to be more efficient than supplementation. Both agronomic biofortification and genetic biofortification have been used to increase Se content of food crops and animal products. Genetic engineering makes use of key genes of Se hyperaccumulators to increase Se accumulating potential of food crops. Agronomic biofortification increases Se content of food crops by adding Se rich fertilizers to the soil or foliar application of Se. Selenium can also be added to animal diets or feedstuff to increase Se content of meat, eggs, and milk. Although inorganic forms of Se are approved as feed additives, they are less efficient than organic sources such as selenomethionine (SeMet) which is the dominant form in plants and animals. Animal products have been found to have higher Se content than plant products with fish having the highest Se content. Fruits and vegetables have a low content of Se probably because of their low protein content. Recommendations for dietary intake of Se vary with country, age and sex. There are concerns that the present recommended Se daily allowance may not be adequate due to discovery of other selenoenzymes with higher Se requirements than gluthathione peroxidase. There may be a need to review the current recommended daily allowance for Se in order to improve human health.
\end{abstract}

Keywords: Selenium, Supplementation, Dietary Intake, Fortification, Selenomethionine

\section{Introduction}

Selenium is an essential nutrient for animals and human but not yet established as an essential nutrient for plants. However, Se has many beneficial effects on plant growth such as growth promoting effect, anti-oxidative effects, senescence delay, and reduced herbivory [1]. Selenium plays a role in many important physiological functions in human and animal health because it's a component of selenoproteins such as glutathione peroxidase, thioredoxin reductase, and thyroid hormone deiodinase families [2]. These Se dependent enzymes play a wide range of biological functions involving thyroid hormone metabolism, the body's antioxidant defense systems, the adaptive and acquired immune system and prevention of certain cancers [3]. In addition, selenoproteins such as glutathione peroxidase and thioredoxin reductase play an important role in maintaining bone homeostasis and protecting against bone loss [4]. Selenium has also been shown to play an important role in the normal functioning of the cardiovascular system even though many studies remain 
inconclusive [3].

Various diseases have been linked with deficiency of Se in both animals and humans. Low dietary intake of Se may cause a number of health problems such as heart diseases, hypothyroidism, reduced male fertility, weakened immune system and enhanced susceptibility to infections and cancer in the human population $[5,6]$. Selenium deficiency is revealed in symptoms such as muscular dystrophy and pain, inflammation of the muscles, fragile red blood cells, necrotic liver degeneration, hair or skin abnormal coloration and exudative diathesis in many warm-blooded animals [7, 8]. However, there is a thin line between Se deficiency and toxicity with high concentrations being toxic [9].

Low Se levels in humans and animals have been associated with low Se levels in the soil because the soil is a source of Se for crops and forages consumed by animals and humans [10]. There are geographic variations in soil Se concentrations around the world, ranging from high concentrations in soils of the USA and Venezuela to low concentrations in Korea, some regions of China and some parts of Europe [11, 12]. Wide differences in geology, soil, climatic factors, foods and fodder from various parts of the world imply a high variability in their ability to provide selenium for dietary intake [13, 14].Many parts of the world such as Europe and Asia are characterized by Se deficiency in soils, crops, animals and humans. About 800 million people worldwide are believed to be deficient in Se [15]. In order to correct the deficiencies and meet the Se daily intake requirements, both animal and human diets are supplemented either directly or via biofortification of forage, animal feed, food crops and food products. Selenium is supplemented through application of either inorganic or organic sources. Both genetic and agronomical fortification can also be used to increase Se levels in food crop and forage to ensure that $\mathrm{Se}$ requirements are met. Selenium is introduced into the food chain via the soil-crop-animal system to increase the daily intake and meet the requirements for both animal and human health.

It is important to understand the origin and impact of Se deficiencies in living systems in order to correct the deficiencies and ensure adequate nutrition of animals and human population for optimum health. Most of the past reviews on Se are on human health and geochemistry. Few have been able to discuss the effect of the soil-crop-animal system on both animal and human health. The goal of this review is to present a holistic soil-plant-animal system of sustaining animal and human health. This review elaborates on $\mathrm{Se}$ in the soil-crop-animal system; it explains supplementation in the livestock industry and supplementation for human health. It also discusses the methods of supplementation, assessment of Se status in tissues, intake recommendations for selenium and types of fortification to correct or prevent Se deficiency in animals and human populations.

\section{Selenium Supplementation in the Livestock Industry}

\subsection{Selenium in the Food Chain}

Selenium in food chain largely influences the selenium nutritional status of humans and animals. Animals predominantly live on plants or plant-based manufactured feeds, whereas human diets include both plant-based foods and animal products (meat, milk, and egg). The Se content of plants is directly affected by plant bioavailable Se levels in the soil in which they are grown, whereas the Se content of animal products (meat, milk, and egg) is determined by the Se levels in the plant-based diets consumed by the animals $[15,16]$. Thus, the ultimate source of Se in the animal and human food chain is plant available soil selenium. Plants take up Se from the soil in the form of selenite or selenate and synthesize selenoamino acids with selenomethionine (SeMet) as the primary compound [17]. In plants, SeMet represents more than $50 \%$ of the total Se [18]; the other selenocompounds in plants include Se-methylselenomethionine, selenocysteine and Se-methylselenocysteine [19]. So, biotransformation of inorganic Se to selenoaminoacids is a crucial physiological process for the entry of Se in the food chain. Since the Se content of plants depend on plant available Se in soil, the level of this element in human foods and animal feed varies in different parts of the world. Over half the world's population (over 3 billion people), mostly women, infants and children in the resource-poor families in the global South, suffer from severe malnutrition of Se and other micronutrients, Fe, Zn, I, etc [20, 21] primarily due to their deficiency in the soils [22]. Likewise, Se deficiency in livestock (Figure 1) is prevalent in many areas of the world [23].

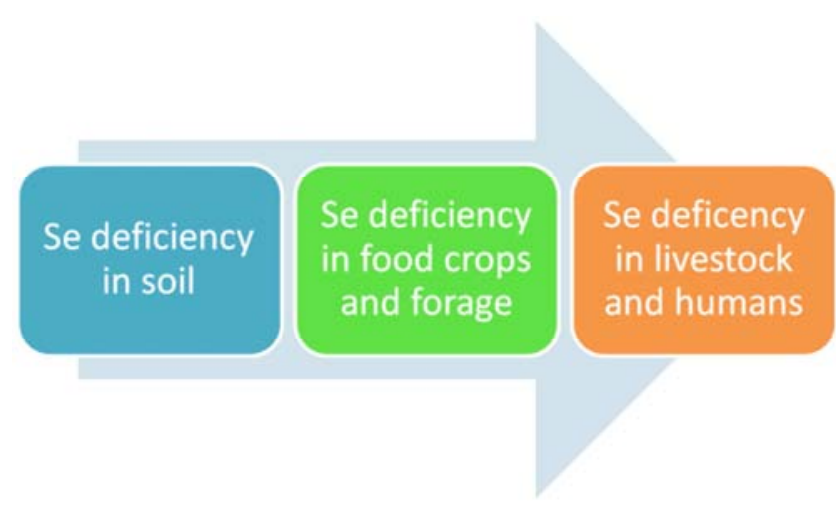

Figure 1. Selenium deficiency.

In contrast, there are places in various countries with seleniferous soils producing plants with toxic concentration of Se $[24,25]$. Because agriculture is the primary source of Se for human and animal nutrition, the Se-deficient agricultural systems must be intervened with appropriate technologies to improving Se status of the food and feed systems that are failing to meet the Se nutritional needs of human and animal [26]. However, such agro-technological 
interventions aimed at improving the Se status of food and feed crops should encompass a holistic food system perspective to assure that the interventions will be sustainable, and adopted by farmers and consumers [27].

\subsection{Approval of Sodium Selenite and Sodium Selenate as Feed Additives by the US Food and Drug Administration}

Feedstuffs (e.g., grains and forages) produced in many areas of the United States are either deficient or at least marginally deficient in Se for desired animal functions. Selenium intake in the diet can be increased by using Se rich feed ingredients or by providing selenized mineral supplements. Selenium deficiency diseases were widespread and severe in the 1960s. This alone caused huge economic losses annually to the livestock and poultry industry, which warranted an emergency fortification of feedstuff with selenium from a suitable source. Both sodium selenite and sodium selenate became promising candidates for this application because of a breakthrough discovery of the antinecrotic activity of Se by [28]. Further studies revealed that these easily accessible inorganic selenium salts at effective dosage levels, unlike the previously tested organic selenium compounds, did not accumulate in organs and tissues to any significant extent. This meant that they could be used as feed additives without violating the "Delaney Clause", which is part of the "1958 Food Additives Amendment and Color
Additives Amendments (section 409)" to the "1954 Federal Food, Drug and Cosmetic Act (FFDCA)" that prohibits the approval of an additive if it is found to induce cancer when ingested by people or animals, or if it is found, after tests which are appropriate for the evaluation of the safety of food additives, to induce cancer in people or animals. However, it was not until 1974, when the U.S. Food and Drug Administration [29], after careful review of the available evidence, approved additions of sodium selenite and sodium selenite to feedstock setting up the initial maximum permissible levels (MPL) of selenium in the feeds.

The initially established MPLs were raised in the early 1980s. The current guidelines [30] for selenized mineral supplements are as follows: 1) manufactured premixes can contain Se up to $200 \mathrm{mg} \mathrm{kg}^{-1}$ and mineral supplements can contain Se up to $11.8 \mathrm{mg} \mathrm{kg}^{-1}$, and 2) the total diet Se content should not exceed $0.3 \mathrm{mg} \mathrm{kg}^{-1}$ and total desired supplement is not over $3 \mathrm{mg}$ head $^{-1}$ day $^{-1}$. This level can, however, be supplemented to diets regardless of the natural Se indigenous in the feedstuffs. The current regulation [30] allows the use of both sodium selenate and sodium selenite as mineral supplements in the feedstuffs. But because of its lower cost, sodium selenite is more commonly used. Sodium selenite is absorbed in the animal body passively via diffusion from the intestinal tract [31]. However, the inorganic Se supplementation (Figure 2) was found to be problematic in various ways.

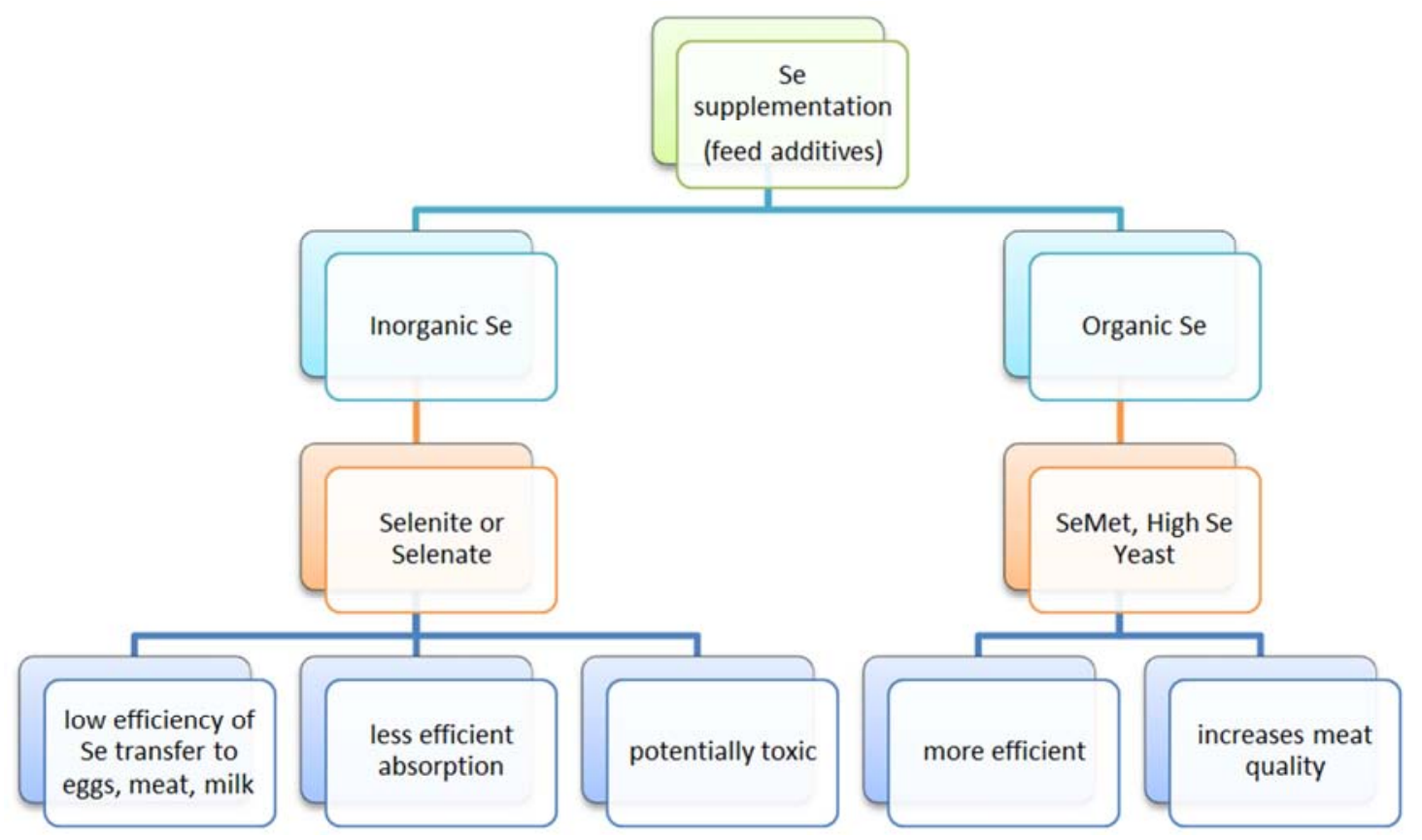

Figure 2. Se Supplementation in Livestock.

First, the absorption of sodium selenite is less efficient and occurs mainly by passive diffusion process [31, 32]. As a result, a greater proportion of consumed inorganic $\mathrm{Se}$ is simply excreted. Thus, supplementation in this form is unable to build and maintain Se reserves in the body. In addition, there is a low efficiency of Se transfer to milk, meat and egg. There are also concerns of potential toxicity via pro-oxidant activity, if the dietary supplementation is too high. Prooxidant activity is the antonym of antioxidant activity (the desired function of $\mathrm{Se}$ ); sodium selenite and some other inorganic Se compounds such as Se dioxide and diselenides have such activity to catalyze the oxidation of thiols such as glutathione with a concomitant production of superoxide and other reactive oxygen species [33]. This catalytic reaction of 
inorganic Se with thiols likely accounts for Se toxicity to cells in the major glutathione producing organs, such as the liver [33].

The pro-oxidant influence of sodium selenite in animals [33] is of particular concern when shelf life of the produced milk, meat and egg is considered [34, 35]. The pro-oxidant property of inorganic Se may also enhance multiplication of some pathogenic viruses. Sodium selenite can interact chemically with vitamin $\mathrm{C}$ (ascorbic acid) in the premix and the chemical reaction between them causes reduction of selenite to elemental Se (it often appears as pink particles in the premixes) and oxidation of vitamin $\mathrm{C}$. The elemental Se is not absorbed in the digestive tract (hence it is excreted) and oxidized vitamin $\mathrm{C}$ is devoid of biological activity [36]. Therefore, nutritional benefits of both Se and vitamin $\mathrm{C}$ are lost. The reduction of selenite to elemental Se could happen in the premix/feed during storage or even in the digestive tract during digestion and absorption. Some other components in the premix like glucose monohydrate, corn starch or sucrose can reduce selenite to elemental $\mathrm{Se}$ in the same way [37].

\subsection{Selenomethionine, the Chief Nutritional Form of Selenium}

The majority of selenium in body tissues and fluids is present as either selenomethionine (SeMet), which is incorporated into general proteins and acts as a biological pool for selenium or selenocysteine (SeCys), which functions as an active center for selenoproteins [38]. It has been reported that irrespective of source, inorganic selenium must undergo a metabolic transformation prior to its assimilation into SeCys and ultimate incorporation into selenoproteins [39]. However, no such intermediate step is necessary for the incorporation of SeMet into general proteins.

Numerous authors [13, 31, 40-42] reported that in the regions with adequate plant bioavailable Se in soils, animals generally remain well-nourished with selenium just by consuming locally grown plant-based feeds which contain Se predominantly as protein-bound Se-Met. On the contrary, in the low Se regions, animals living predominantly on locally grown plant-based diets suffer from varying degree of Sedeficiency disorders. To combat Se-deficiency in the low Se regions, animals are often raised on feed fortified with sodium selenite; however, they still remain nutritionally deficient in Se to varying degrees, because these inorganic selenite and selenate supplements are not the natural nutritional form (which is indeed SeMet) of the element for the animals and the metabolic fate of inorganic Se differs substantially from that of SeMet.

Although, the rumen bacteria are able to produce some SeMet, the pertinent literature suggests that the amount of SeMet supplied from this source is indeed limited and does not meet the total needs of the animals [43]. As a result, supplementing SeMet produced measureable beneficial effects in both dairy and beef cattle industry. [44] reported that when dairy cows that were fed to Sel-Plex, a source of organic nutritional selenium primarily in the form of SeMet, they produced milk with a substantially higher selenium content and with a lower somatic cell count than the milk of control animals receiving the same amount of selenium as sodium selenite. Feeding Sel-Plex also increased the selenium content of blood, skeletal muscles, and in colostrum of calving cows. The Se-rich colostrum is highly beneficial to the immunity and survival of the calves. As SeMet is also naturally present in animal muscles [45], supplementation with SeMet increases meat quality as well, providing the basis for the commercial production of Se-rich meat that would improve human Se-nutrition [43]. In poultry, when feed contained SeMet, the layers produced eggs with a substantially higher SeMet content [46]. The other studies provided unequivocal evidence that humans retain substantially more Se in their organs and tissues when they obtain this micronutrient in the form of SeMet than from sodium selenite or selenate.

\subsection{High Selenium Yeast as a Source of Food-Form Organic Selenium}

The fermenting yeast, Saccharomyces cerevisiae was reported as early as 1961 to assimilate inorganic Se from the culture medium and to convert it into SeMet [47]. In selenium-rich growing media, during synthesis of selenium S-containing methionine, Se substitutes for sulfur in the structure of methionine, thus forming SeMet, which becomes part of yeast protein. The selenium yeast is valuable in animal and human nutrition, because it contains Se-Met which is the predominant organic form of selenium produced by food-chain autotrophs such as most plants and certain blue-green algae [40, 48].

The first batches of Se yeast reached the marketplace in 1974 by the "Universal Foods (a leading producer of food yeast in the US in 1970s)" on initiative of "Nutrition 21 (a California-based nutritional supplement company)". The Seyeast rapidly gained popularity as a feed additive, although it remained unapproved for this purpose until the year 2003, when Alltech, Inc. succeeded in having their product, "SelPlex", FDA approved for all animal species. The Saccharomyces cerevisiae, grown in a selenium-rich media, is now a recognized source of organic food-form selenium [48]. At present, several companies produce and market Se yeast, and it is the most widely used source of Se for human supplementation. Selenium yeast is also increasingly employed in animal nutrition, since its use is FDA-approved since 2003. The maximum amount of Se that a yeast cell can theoretically incorporate depends on its methionine content and can be in the order of $6000 \mathrm{ppm}$ for replacement of Met by SeMet. However, such full replacement is not achievable in practice; the highest amount of Se in yeast achieved so far is about $3000 \mathrm{ppm}$. The commercial culture Se yeast is tuned to contain from 500 to $2000 \mathrm{ppm}$ of Se, most of them containing about $1000 \mathrm{ppm}[13,40]$.

Inclusion of selenium yeast as a supplement in the animal diets not only benefits animal health and performance, but also offers an added nutritional benefit to human consuming food-animal products. The SeMet containing plant or yeast 
protein consumed by animals can be also stored in animal protein, which can result in bioactive selenium content in meat, milk, and eggs with potential human health benefits. As a result, supplementation of animal diets with selenium yeast contributed to the development of selenium-rich functional foods, including selenium-enriched milk, eggs and meats for human consumption [49-52]. Pure selenomethionine is also known as a toxic substance. However, a fetal toxicity to an adult could be expected when oral intake of SeMet is as high as $1 \mathrm{~g}$. Thus Se yeast poses no considerable serious toxicity threat because to obtain $1 \mathrm{~g}$ of SeMet, as much as $1 \mathrm{~kg}$ of Se yeast containing $1000 \mathrm{ppm}$ SeMet would have to be ingested. The chronic toxicity of Se yeast has been reported to be lower compared to sodium selenite in experiments with young rats [53] and growing pigs [54]. However, young, growing animals could be less sensitive to chronically toxic levels of Se-Met because most of the ingested SeMet could be continuously incorporated into newly synthesized proteins and removed from circulation. The chronic toxicity of SeMet is still to be investigated and established. Nevertheless, the safety record of Se yeast is excellent. No cases of accidental Se poisoning have been reported over the last four decades of its use as a feed additive and in nutritional supplements.

\subsection{Selenium Deficiency Versus Selenomethionine Deficiency}

The fact that "Selenium Deficiency" is indeed "SeMet Deficiency" is a resolved issue in research, but it is still unresolved in applications. It is still very common that whenever low selenium levels or deficiency disorders related of this element are observed in animals and humans the term selenium deficiency instead of SeMet Deficiency is applied. A distinction between the two types of deficiencies is necessary because a failure to distinguish between the two may result in the adoption of the wrong treatment or prevention strategies. [55] studied the effect of source and the dosage of Se supplementation on Se in eggs and blood variables of poultry. After supplementing the diets for $56 \mathrm{~d}$, they observed significantly higher Se levels in serum and egg for the Se-supplemented groups compared with the unsupplemented control. It was also noted that Se from the two organic sources, L-SeMet and Se-enriched yeast, was more bioavailable than the sodium selenite as evidenced by blood and egg Se levels. Within the organic Se sources, LSeMet showed higher Se transfer to eggs than Se-enriched yeast.

In human, Keshan Disease (KD) is an excellent in this context. The KD has a complex etiology, it is an endemic and often manifests as cardiomyopathy primarily among infants and young women consuming exceptionally low-selenium wheat and corn produced in the selenium deficient regions of China. The initial approach of addressing KD during 1974-77 was largescale Se supplementation with $0 \cdot 5-1 \mathrm{mg}$ sodium selenite tablet per week. Although this approach tremendously reduced the disease incidence, the protection was not long-lasting. Low salt tolerance prevented the administration of sufficiently large doses of inorganic sodium selenite in the most vulnerable infants and small children, which acted as a barrier to protect them from KD by this approach. Implementing an alternate approach, [56] demonstrated much more substantial and sustainable increases of blood selenium levels could be achieved by supplementing with Se-Met instead of sodium selenite leading to the realization the selenium deficiency in the KDendemic regions was indeed deficiency of organic SeMet rather than inorganic Se. From that point forward, it was emphasized that eating foods naturally rich in Se would be more effective than inorganic sodium selenite supplementation. This method also offered a better solution to the selenium deficiency disorders in the district of Chita, which is a low-selenium region of the former USSR, where they simply provided the people with Se-rich wheat imported from the USA [57].

\subsection{Assessment of Selenium Nutritional Status in Animals}

Assessment of Se nutritional status of animal assists in evaluating and ensuring neither deficiency nor toxicity potential exists. There are several recommendations with regards to the method of adequate assessment of $\mathrm{Se}$ nutritional status of animals. These include the use of selenium concentration in blood-serum/plasma (without cells), whole blood (with cells), and hepatic, renal and muscular tissues (but primarily liver tissues). Selenium status can also be assessed by determining glutathione peroxidase (GSH-Px) activity in whole blood.

Determination of selenium in blood and tissues provides a direct assessment of selenium status, whereas GSH-Px activity in whole blood provides an indirect assessment of selenium status. The assessment of selenium status by measurement of GSH-Px activity is based on its biological functions as antioxidant system of the animal. However, laboratories that offer GSH-Px analysis are limited and it is a more expensive and technically difficult procedure. Liver Se content is a good indicator of Se status, but one must obtain a liver tissue sample either by biopsy on a live animal or from a dead animal. It is well worth the cost to have liver mineral analyses completed on any animal that dies (young or old) as a routine monitor of nutritional status. Analyzing the Se concentration and GSH-Px activity in whole blood of 326 cattle from 30 herds in Czech Republic, [58] observed a close and significant correlation between these two variables $(\mathrm{r}=$ $0.90 ; p<0.01)$. The regression line, defined by the equation $y$ $=6.44 x+21.4$, allowed the determination the GSH-Px activity of $665.4 \mu \mathrm{kat} \mathrm{L}^{-1}$ as equivalent to Se concentration in whole blood $100 \mu \mathrm{g} \mathrm{L}^{-1}$. These levels were used in diagnosis of insufficient Se in cattle in the Czech Republic.

Most laboratories perform either serum or whole blood Se concentration analyses. Serum Se concentration reflects more acute or recent changes in Se nutrition, whereas whole blood Se reflects more chronic or historical Se status. In some animals the GSH-Px resides primarily in the red blood cells, where whole blood Se level serves a better assessment of Se status. In some other animals, more GSH-Px exists outside 
the red blood cell, where serum Se level is more useful. Selenium concentrations in serum and whole blood in a given animal species also varies by age of the animal. [59] suggested that the adequate level of selenium in the whole blood of cattle is between 0.08 and $0.16 \mathrm{mg} \mathrm{L}^{-1}$. In serum/plasma, the appropriate level in plasma selenium has been reported to be between 51 and $85 \mu \mathrm{g} \mathrm{L^{-1 }}$ [60]. According to National Research Council [61], a dietary intake of $0.5 \mathrm{mg} / \mathrm{kg} \mathrm{DM}$ may be enough to achieve this adequate blood Se level. Generally, an increase in the concentration of selenium in the diet results in an increase of the selenium concentration in the serum within 2-6 days after intake [62, 63]. Selenium supplementation in diets usually results in an increase of the selenium content and GSH-Px activity in the blood of calves [64], heifers [65] and fattening bulls [66]. Such positive effects become more pronounced when Se is supplemented in organic form as compared to inorganic form [65, 67]. Generally, organic Se supplementation resulted in an estimated $20 \%$ increase $\mathrm{Se}$ level and 16\% increase in GSH-Px activity in blood [68].

\subsection{Efficacy of Various Types of Selenium Supplementation}

Research works have reported evidence that the biological potency of organic Se-Met is much better than inorganic selenite. The most probable reason for this difference lies with the fact that Se-Met can reach the amino acid pool directly, whereas before inorganic selenite could be incorporated to the body proteins/enzymes, they require reductive transformation processes during their passage through the intestinal membranes. Availability of transporter molecules such as cysteine (Cys) or glutathione (GSH) determines the rates of these reductive transformation processes of selenite. In contrast, selenate is not as easily reducible as selenite. [69] reported that selenite is actively transported through the membranes of the small intestine as such and subsequently reduced primarily in the liver. Reduced inorganic selenite or selenate by cysteine (Cys) and glutathione (GSH) exist as selenodicystine and selenodiglutathione, respectively, forming exchangeable selenium pool. The reduced selenium species undergo further transformations to the forms needed for the biosynthesis of the ultimate form, selenoenzymes. In studies with New Zealand women, the selenium absorption from selenite reached $44-70 \%$, compared to $96 \%$ from Se-Met [70, 71], while [72] observed $84 \%$ selenium absorption from selenite and $98 \%$ from SeMet. In addition to selenodicystine and selenodiglutathione, the Se-exchangeable pool contains numerous other selenium species, including endogenously synthesized selenoproteins (e.g. GSH-Px, selenoprotein P, etc), excretory selenium metabolites (such as the trimethylselenium ion), selenosugars, etc [50, 73-74]. The SeMet is not included, which explains why none of the selenite-derived selenium species in the Se-exchangeable pool are significantly retained in body proteins. Instead they are excreted with the feces, the urine, or are methylated and exhaled. Through another biological pathway, some of the selenium from the Se-exchangeable pool also reacts with arsenic, mercury, cadmium, and other toxic elements. These interactions are part of the natural toxic-elementdetoxification processes and form soluble or insoluble metal selenides or protein complexes, which are stored in liver and kidneys. The selenium stored in this way is generally not reusable. If human or animal body is exposed to toxic elements in a continuous manner, a substantial proportion of consumed Se would be sequestered in the detoxification processes, leaving less Se for the primary beneficial bioactive functions [43].

\section{Selenium Supplementation for Human Health}

\subsection{Background}

Selenium was originally detected as a covalently bound component in mammalian glutathione peroxidase, an antioxidant enzyme [75-76]. Selenocysteine, the $21^{\text {st }}$ amino acid, is the key component of several selenoproteins with enzymatic functions such as redox homeostasis, thyroid hormone metabolism, and protection from oxidative stress and inflammation [77]. There are 25 selenoproteins in humans including glutathione peroxidases, thioredoxin reductases, and iodothyronine deiodinases [4]. Selenium required for human health can be supplied through supplementation, diet and food fortification. Selenium supplementation has been shown to be involved in reduction of susceptibility to viral-induced cardiomyopathy experienced by patients with Keshan disease [78-79]. Recently, a 15 month old boy with dilated cardiomyopathy responded to six months of Se supplementation along with anti-failure therapy. Cardiac function, hair, skin and general health of the patient improved significantly indicating Se deficiency as the probable cause [80]. Selenium supplementation increased serum Se levels which decreased HIV viral loads in HIV infected men and women [81]. In the same way, Se supplementation increased serum Se levels, increased vigor and reduced anxiety of HIV infected patients [82]. However, these results are not sufficient enough to recommend Se supplementation in patients with HIV [83]. An inverse relationship was reported between dietary selenium intake and cancer mortality [84]. Daily supplementation with high selenium yeast also significantly lowered the cancer risk among US American men with low baseline selenium levels while another study found no association between plasma selenium level and prostate cancer risk [85-86]. The effectiveness of selenium supplementation might be influenced by the nature of the selenocompound used and its dose, the initial selenium status and the genetic background, the form of cancer and the time point of intervention [87]. It is important to note that Se supplementation has been associated with increased risk of type 2 diabetes especially in men with high baseline plasma Se [88-90]. Past studies have shown that inorganic selenium can enhance insulin sensitivity by mediating insulin-like 
actions [91-92]. On the contrary, high plasma selenium was also associated with a decreased risk of onset of impaired fasting glucose or diabetes in men [93].

\subsection{Selenium in the Human Diet}

Even though supplementation may be beneficial for people living in environments with low Se in food crops and soil, diet is still the main source of Se for the human population [94]. Human Se requirements can be provided in regular consumption of food with high concentration of Se. Se occurs in both inorganic and organic forms but is predominantly present as selenomethionine (SeMet) in food of plant origin while those of animal origin contain both SeMet and selenocysteine (SeCys) [95-96]. The Se concentration of food of both plant and animal origin depends on the protein content [97-98] with organs such as kidney and liver having a potential to accumulate Se [99]. Animal products such as meat and fish tend to be richer in $\mathrm{Se}$ than plant materials [100]. The highest Se content in food is found in fish products (Table 1). Shrimp is one of the most important food sources of Se in the diet because it has a major ability to accumulate the element [98]. Seafood, meat products, cereals, and bread are the foods that mainly contribute to the daily dietary intake of $\mathrm{Se}$ in healthy individuals from South-eastern Spain due to their high Se concentrations and frequent consumption in the diet [101]. Wheat is an efficient accumulator of Se and one of the main sources of dietary Se for the human population [102]. Wheat is estimated to supply nearly half the Se utilized by most Australians [102]. Selenium levels ranging from 87.6 to 737 $\mathrm{ng} \mathrm{\textrm {g } ^ { - 1 }}$ were reported in meat, chicken, fish and eggs [103]. Selenium concentration in human milk is greater than in milk from animals such as sheep, goat and cow [104]. Fruits and fresh vegetables are poor sources of Se probably due to their low protein content [105]. However, vegetables such as broccoli, Brussel sprouts, cabbage, cauliflower, collards, mustards, garlic, chives and onions tend to have higher Se concentrations [106-107]. Protein-rich nuts such as pistachios, walnuts and Brazil nuts have high Se concentrations [106]. Selenium concentrations up to $3800 \mathrm{ng}$ $\mathrm{g}^{-1}$ were reported for Brazil nuts [108].

Table 1. Selenium content of food.

\begin{tabular}{|c|c|c|c|c|}
\hline Food & Saudi Arabia & Greece & Slovenia & Spain \\
\hline Meat & $0.22-0.66$ & 71.7 & $35-128$ & NA \\
\hline Egg & 0.23 & 123 & $61-70$ & NA \\
\hline Cereals & $0.04-0.16$ & NA & NA & 27.8 \\
\hline Legumes & NA & 162.5 & NA & 112 \\
\hline Vegetables & 0.001 & 6.5 & $0.3-76.7$ & NA \\
\hline Fruits & 0.067 & 3.4 & $0.6-11.6$ & 295 \\
\hline Fish & NA & 246 & $153-686$ & NA \\
\hline Bread & NA & 91.9 & NA & NA \\
\hline Units & $\mu \mathrm{g} / \mathrm{g}$ & $\mathrm{ng} / \mathrm{g}$ & $\mathrm{ng} / \mathrm{g}$ & $\mathrm{ng} / \mathrm{g}$ \\
\hline References & Al-Ahmary, 2009 & Pappa et al., 2006 & Smrkolj et al., 2005 & Diaz-Alarcon, 1996 \\
\hline
\end{tabular}

\subsection{Human Dietary Selenium Intake}

The concentration of $\mathrm{Se}$ in food and amount of food consumed determines the dietary intake of Se [109]. The dietary intake of selenium varies considerably around the world (Table 2) because of the large variability in geochemistry which determines the selenium content of foods [110-111]. Different countries also have different cultural foods and staples in their diet which determines Se intake. In a bid to correct and prevent deficiency diseases associated with low Se status, many countries have estimated and recommended daily requirements for Se [95]. The recommendation for daily intake of Se is determined by each country based on levels that maximize the activity of glutathione peroxidase (GSH-Px) in plasma [112]. The recommended daily intake of Se varies with age, sex and reproductive condition of the female population. For example, the recommended dietary allowance for lactating women $\left(70 \mu \mathrm{g} \mathrm{day}^{-1}\right)$ is greater than that of the pregnant women $\left(60 \mu \mathrm{g} \mathrm{day}^{-1}\right)$ in the USA [113]. However, they are the same $\left(30-70 \mu \mathrm{g} \mathrm{day}^{-1}\right)$ in some parts of Europe (Germany, Austria, Switzerland) [113].
The recommended daily intake of Se is much lower in children than adults regardless of country. It varies from 10$45 \mu \mathrm{g}$ day $^{-1} ; 15-40 \mu \mathrm{g}$ day $^{-1} ; 12-50 \mu \mathrm{g}$ day $^{-1}$ for children under the age of $14 \mathrm{yrs}$ in UK, USA and New Zealand/Australia respectively [113]. The recommended dietary allowance of $55 \mu \mathrm{g} \mathrm{day}^{-1}$ for adults in USA is slightly lower than the United Kingdom reference nutrient intake (RNI) of $75 \mu \mathrm{g} \mathrm{day}^{-1}$ for men and $60 \mu \mathrm{g}$ day $^{-1}$ for women while the World Health Organization/Food and Agriculture Organization/International Atomic Energy Agency (WHO/FAO/IAEA) recommended a minimal intake level of $40 \mu \mathrm{g} \mathrm{Se} \mathrm{day}^{-1}$ for men and $30 \mu \mathrm{g} \mathrm{Se}$ day $^{-1}$ for women [114]. The United Kingdom and other European countries have mean intake levels that are approximately half the RNI, while intakes of less than $19 \mu \mathrm{g} \mathrm{Se}$ day $^{-1}$ for men and less than 13 $\mu \mathrm{g} \mathrm{Se}$ day $^{-1}$ for women have been reported in some parts of China [114].

Table 2. Daily Se Intake in different countries.

\begin{tabular}{lll}
\hline Country & Se Intake $\left(\boldsymbol{\mu g}\right.$ day $\left.^{-1}\right)$ & References \\
\hline Spain & 15.4 & Diaz-Alarcon et al., 1996 \\
Croatia & 27.3 & Klapec et al, 1998 \\
Brazil & 37 & Maihara et al., 2004 \\
\hline
\end{tabular}




\begin{tabular}{lll}
\hline Country & Se Intake $\left(\boldsymbol{\mu g}\right.$ day $\left.^{-1}\right)$ & References \\
\hline Greece & 39.3 & Pappa et al., 2006 \\
Germany & $38-47$ & Oster and Prellwitz, 1989 \\
Belgium & 60 & Waegeneers et al., 2013 \\
Netherlands & 67 & Foster and Sumar, 1997 \\
Switzerland & 70 & Foster and Sumar, 1997 \\
Slovenia & 87 & Smrkolj et al., 2005 \\
Japan & $82.7-118$ & Miyazaki et al., 2004 \\
Saudi Arabia & $75-122$ & Al-Ahmary, 2009 \\
USA & $90-134$ & Waegeneers et al., 2013 \\
\hline
\end{tabular}

About a decade ago, the average daily intake of Se in China was $69.2 \mu \mathrm{g} \mathrm{day}^{-1}$ (79.9 and 53.1 $\mu \mathrm{g} \mathrm{day}^{-1}$ in urban and rural areas, respectively) in adult women when analyzed by instrumental determination and $35.1 \mu \mathrm{g} \mathrm{day}^{-1}$ (36.7 and 32.7 $\mu \mathrm{g}$ day $^{-1}$ ) by Food Composition Tables-based estimation [115]. The differences in daily intake for China may be due to either a decrease in intake over the years or may be a reflection of the Se content of the soil which varies greatly across regions. China is known for having both Se deficient areas and seleniferous soils in different parts of the country. The mean dietary selenium intake in Belgium was calculated to be $60 \mu \mathrm{g} \mathrm{day}^{-1}$, which is at the lower end but within the range recommended by the Superior Health Council in Belgium (60-70 $\left.\mu \mathrm{g} \mathrm{day}^{-1}\right)$, and adequate according to the 55 $\mu \mathrm{g}$ day $^{-1}$ recommended by the Scientific Committee on Food (SCF) of the European Commission [116]. Daily Se intake below $55 \mu \mathrm{g}$ day $^{-1}$ was reported for European countries such as Greece, Turkey, Spain, Poland, Croatia and Austria while Switzerland and Netherlands had above $60 \mu \mathrm{g}$ Se day ${ }^{-1}$ [109]. In Germany, the dietary selenium intake of men is $47 \mu \mathrm{g}$ day ${ }^{1}$ and that of women $38 \mu \mathrm{g} \mathrm{day}^{-1}$ (Oster and Prellwitz, 1989). Animal protein was the main source of dietary selenium in Germany accounting for $65.5 \%$ of the total selenium intake [117].

\subsection{Recommended Daily Allowance (RDA) of Selenium Whether Current RDA Is Enough}

In the US, the Food and Nutrition Board (FNB) at the Institute of Medicine of the National Academies (formerly National Academy of Sciences) developed the Dietary Reference Intakes (DRIs) in which the intake recommendations for selenium and other nutrients are provided [118]. The term "DRI" is the general term used for a set of reference values used for recommending and assessing nutrient intakes of healthy people, which can vary with age and between male and females. These values are as follows;

1) Recommended Dietary Allowance (RDA), which is the average daily level of intake sufficient to meet the nutrient requirements of nearly all $(97 \%-98 \%)$ healthy individuals in a defined group. 2) Adequate Intake (AI), a level established when evidence is insufficient to develop an RDA and is set at a level assumed to ensure nutritional adequacy. 3) Tolerable Upper Intake Level (TUL): maximum daily intake unlikely to cause adverse health effects. 4) Estimated Average Requirement (EAR), which is the average daily level of intake estimated to meet the requirements of $50 \%$ of healthy individuals. It is usually used to assess the adequacy of nutrient intakes in population groups but not individuals.

Table 3 lists the current RDAs and TULs (from food and supplements taking into account the amounts of selenium that are associated with hair and nail brittleness and loss) for selenium in micrograms $(\mu \mathrm{g})$ as adopted by [118]. However, the FNB failed to specify the chemical form of selenium for supplementation and the maintenance of health in its recommendations despite the fact that the biological potency of organic (yeast) selenium is much better than inorganic selenite.

Table 3. Recommended Dietary Allowances (RDAs) and Tolerable Upper Intake Levels (TULs) for selenium in mcg.

\begin{tabular}{lllllllll}
\hline Age & Male & Male & Female & Female & Pregnancy & Pregnancy & Lactation & Lactation \\
\hline & RDA & TUL & RDA & TUL & RDA & TUL & RDA & TUL \\
Birth to $6 \mathrm{~m}$ & $15^{\dagger}$ & 45 & $15^{\dagger}$ & 45 & & & \\
$7-12 \mathrm{~m}$ & $20^{\dagger}$ & 60 & $20^{\dagger}$ & 60 & & & \\
$1-3 \mathrm{y}$ & 20 & 90 & 20 & 90 & & & \\
$4-8$ y & 30 & 150 & 30 & 150 & & & \\
$9-13$ y & 40 & 280 & 40 & 280 & & 400 & 400 \\
$14-18$ y & 55 & 400 & 55 & 400 & 60 & 400 & 400 \\
$19-50$ y & 55 & 400 & 55 & 400 & 60 & & \\
$51+$ y & 55 & 400 & 55 & 400 & & & \\
\hline
\end{tabular}

Breast milk, formula, and food should be the only sources of selenium for infants.

For infants from birth to 12 months, the Food and Nutrition Board (FNB) established an AI for selenium that is equivalent to the mean intake of selenium in healthy, breastfed infants.

${ }^{\dagger}$ Adequate Intake (AI). Note: For infants from birth to 12 months, the FNB established an AI for selenium that is equivalent to the mean intake of selenium in healthy, breastfed infants.

[43] argued that despite the existence of numerous credible scientific literature with suggestions of $200-300 \mu \mathrm{g} \mathrm{day}^{-1}$ as the optimal selenium intake for health maintenance, the currently adopted (by FNB) RDAs for selenium of $55 \mu \mathrm{g}$ day ${ }^{1}$ for men and women over 19 years of age, $60 \mu \mathrm{g} \mathrm{day}^{-1}$ for pregnant women, and $70 \mu \mathrm{g}$ day $^{-1}$ during breast feeding would have to be concluded either too low or clearly inadequate. The biological function of $\mathrm{Se}$ was initially assigned solely to its involvement in the activity of glutathione peroxidase (GSH-Px) selenoenzymes. Accordingly, the RDA values are based on the amounts of selenium theoretically needed by an adult of average weight to maximize GSH-Px activity. However, several other additional selenoenzymes have been discovered, some of 
which, such as the thioredoxin reductases, require significantly higher selenium intakes than GSH-Px for their maximum activity. This necessitates an elevation of the RDAs. [119] reported the "physiological selenium requirement' of $80 \mu \mathrm{g} \mathrm{day}{ }^{-1}$ for men and $57 \mu \mathrm{g} \mathrm{day}^{-1}$ for men and women, respectively; the current RDAs are lower than these established requirements. The physiological selenium requirement, which represents the amount of selenium needed to maintain selenium balance in the body, a gradual depletion of selenium reserve in the body would occur due to constant adherence to the current RDAs.

[120] observed that pregnant women in China receiving $100 \mu \mathrm{g}$ of supplemental Se $\mathrm{day}^{-1}$ for 6-8 weeks had significantly lower incidence of edema and hypertension. Low selenium intakes have been shown to increase the risk of toxemia, nephropathy, edema, pre-eclampsia, placenta retention, hypertension, and stroke. Low selenium intakes during pregnancy may also harm the fetus. [43] emphasized that the RDA of $60 \mu \mathrm{g} \mathrm{Se}$ day $^{-1}$ for pregnant women may not provide sufficient protection against complications during pregnancy and at birth. Likewise the current RDAs for infants, children, adolescents, and pregnant and lactating women are also too low. A depletion of Se in the milk along with a depletion of selenium reserves in the body of the lactating women may often occur if the pertinent RDA of 70 $\mu \mathrm{g} \mathrm{Se} /$ day is followed during the lactation period. [121] demonstrated that these declines were prevented with an intake of $100-200 \mu \mathrm{g} \mathrm{Se}$ day $^{-1}$ in the form of organic selenium (as in Se-yeast).

Furthermore, the current RDAs for selenium are also problematic in the sense that they ignored the high affinity of selenium for a number of toxic metals such as mercury and cadmium, and of metalloids such as arsenic, and several others, which naturally occur and enter the human body in various ways. This property enables Se to function as a detoxifying agent of these toxic elements, but renders itself metabolically inactive in the other relevant biological processes. [43] Suggested that at an intake of 200-300 $\mu \mathrm{g}$ day $^{-1}$, the deleterious effects of these toxic elements the organism could be significantly counteracted as well as adequate selenium would be left available for its other biological functions.

\section{Biofortification of Selenium in Food and Feed Crops}

\subsection{Background}

Biofortification is the process of increasing the bioavailable concentrations of essential elements in edible portions of crop plants through the use of fertilizers (agronomic biofortification) or through crop selection or breeding (genetic biofortification) [102, 122]. Agronomic biofortification (Figure 3) involves the enrichment of soils with Se using Se fertilizers to correct and augment the deficiency of Se in soils. This is important because low dietary intake of Se has been associated with low Se status of the soil. Low Se status of the soil leads to low Se uptake by plants used as forage for animals or food for the human population. There is a wide variability in capability of different plant species to accumulate Se. Some plants are accumulators while some others are Se accumulators with a natural tendency to concentrate $\mathrm{Se}$ in their tissues. Selenium hyperaccumulators are able to accumulate greater than 1000 $\mathrm{mg} \mathrm{kg}^{-1} \mathrm{Se}$ in their shoots. Identification of key genes in Se hyperaccumulators may lead to future genetic engineering approaches [123]. Genetic engineering attempts to exploit genotypic variation in Se accumulation in crops to select or breed varieties with increased Se which will minimize the need to use Se fertilizers [122, 124]. It identifies key genes for Se accumulation or hyper-accumulation in plants, and delivers them to target plants or crops to improve their capacity of Se enrichment ([8]. Selenium biofortification efforts makes use of the natural variation in Se accumulation between plant species, and choose crop species that naturally tend to contain higher Se (and S) levels, such as Brassica and Allium species [15, 41].

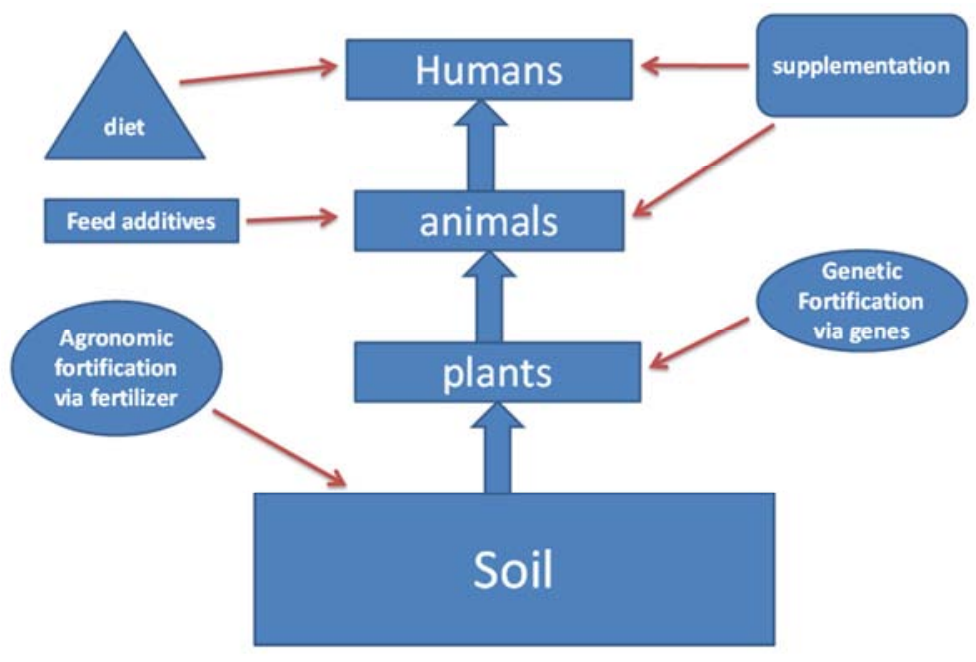

Figure 3. Selenium transfer through the soil-plant-animal system. 


\subsection{Genetic Biofortification}

It is possible to enrich food crops in the longer term by selecting or breeding crop varieties with enhanced Se accumulation characteristics [122]. Genetic engineering has been used to produce new genotypes which are able to accumulate higher Se concentrations in bioavailable forms [15]. Genetic engineering of the $\mathrm{S} / \mathrm{Se}$ assimilation pathway has been used to enhance plant Se tolerance, accumulation and volatilization [123]. Key genes for Se accumulation cloned from plants include Selenocysteine Methyltransferase (SMT), ATP Sulfurylase (APS), AtCpNifS, Glutathione Synthetases (GS), and Cystathionine- $\gamma$-synthase (CGS) (Guo et al., 2014). SMT transforms a large proportion of SeCys to non-poisonous MetSeCys which greatly reduces the chances of incorporation of SeCys and SeMet into protein which significantly increased Se tolerance in plants [125-126]. ATP Sulfurylase is a rate-limiting enzyme in Se metabolic pathways [8]. AtCpNifS can convert SeCys into $\mathrm{Se}$ and alanine by Selenocysteine lyase. Cystathionine- $\gamma$-synthase (CGS) is the key enzyme for methionine synthesis. Most of the work on genetic biofortification has been done with Brassica juncea probably because the species is an efficient Se accumulator and protein source for ruminants [127]. Overexpression of ATP sulfurylase (APS) in Brassica juncea resulted in the transgenic APS plants accumulating organic Se when supplied with selenate, while wildtype controls accumulated selenate. The transgenic APS plants also accumulated more Se than the controls [128]. Similarly when SeCys methyltransferase (SMT) was overexpressed in $A$. thaliana and $B$. juncea, SMT transgenics showed enhanced Se accumulation predominantly in organic form [129]. Double-transgenic plants (APS X SMT) accumulated up to 9 times higher Se levels than wild type [126]. Selenium accumulation in Brassica juncea was 2.3 times higher than that in the wild type plants when GS was incorporated [130]. Similarly, APS and GS transgenic Indian mustard plants accumulated 4.3 and 2.3 times higher Se in leaves than the wild type plants respectively [131]. CGS incorporation in transgenic Brassica juncea plants enhanced their tolerance and increased Se enrichment compared with the wild type plants [132].

\subsection{Agronomic Biofortification}

Both foliar application and fertilizer soil applications can be used to increase Se uptake in food crops or forages. Fertilizer application and foliar application of Brassica species with inorganic Se led to high accumulation of SeMet and its stability during processing [127]. Food fortified with selenium has proved to be more efficient than supplementation probably because they provide Se in a more bioavailable form. For example, selenium enriched garlic was more effective in the reduction of breast cancer development than selenium-enriched yeast [133]. [134] showed that foliar application of Se as potassium selenate is an efficient agronomic approach to improve seed $\mathrm{Se}$ concentration for lentil consumers. Results of their study showed that foliar application increased seed $\mathrm{Se}$ concentration from 201 to $2772 \mu \mathrm{g} \mathrm{kg}^{-1}$. They reported that consumption of $20 \mathrm{~g}$ of biofortified lentil can supply all of the recommended daily allowance of Se. Consumption of Sebiofortified wheat was found to increase plasma $\mathrm{Se}$ concentration from a baseline level of 122 to $192 \mu \mathrm{g} \mathrm{L}$ ${ }^{1}$ [135]. However, improvement of Se status by consumption of Se-biofortified wheat did not substantially modify the selected biomarkers of degenerative disease risk and health status in selenium replete cohort of healthy older men in South Australia. Substitution of Se-deficient wheat by wheat naturally enriched with Se and its products contributed to the increase of daily intake on the average by $18 \mu \mathrm{g}(12-35$ $\mu \mathrm{g})$ in volunteers, which is more than $50 \%$ of the average daily intake. The increased Se intake induced an increase in GSH-Px activity in blood and decreased concentrations of TBARS, lipid parameters, and glucose in blood [136].

Rice produced in Italy is characterized by low content of selenium mostly due to the low content of selenium in soil of the production area [137]. Selenium food fortification was proposed as a strategy to counteract the inadequacy of selenium intake among the Italian population. Hence, a study was conducted to determine the effect of foliar fertilization of an Italian rice cultivar with sodium selenate on serum selenium. Selenium fortification of rice increased the serum selenium levels and GSH-Px activity after 20 days intake of this Se-enriched-rice [138]. Finland carried out a nationwide fertilization of their Se deficient soils by supplementing fertilizers with Se in the chemical form of sodium selenate due to an extremely low daily Se intake in the 1970s. This led to an increase of selenium concentration in cereals 15-fold compared with the level before the Se fertilization. The mean increase in the Se concentration in beef, pork and milk was 6-, 2- and 3-fold respectively. Consequently, the average dietary human intake increased from $40 \mu \mathrm{g} \mathrm{Se}$ day $^{-1}$ in 1985 to a present plateau of $80 \mu \mathrm{g} \mathrm{Se}$ day $^{-1}$, which is well above the current nutrition recommendations [10]. The decline in Se daily intake in the UK from the 1970 s to the 1990 s was attributed to replacement of milling wheat having high levels of grain $\mathrm{Se}$ and grown on high Se soils in North America with UK sourced wheat having low levels of grain Se and grown on low-Se soils. Biofortification to enrich UK-grown food crops using Se fertilizers was proposed as the solution [122]. In Chile, endophytic bacteria (Acinetobacter sp. E6.2 and Bacillus sp. E5) has been shown to enhance Se content of food plants and can be used for biofortification of food crops in the Se deficient Chilean Andisols [139].

\subsection{Food Fortification: Meat, Milk, and Eggs}

The goal of food fortification is to increase the concentration of Se in food such as meat, milk and eggs by supplementation of basal diets or animal feeds. The response to supplementation of animal diets depends on the source and dose of Se [140]. Selenium can be supplied in animal diets 
either as the organic or inorganic form. Inorganic forms of Se (such as selenates and selenites) and organic forms such as SeMet, SeCys and methylselenocysteine (MetSeCys) are widely used as nutritional selenium sources [141].

Feeding chickens up to $5.1 \mu \mathrm{g} \mathrm{g}^{-1}$ of inorganic and organic forms of Se did not affect egg production and the welfare of the laying hen [142]. This suggests that fortification with inorganic and organic sources of $\mathrm{Se}$ is a practical way of producing Se-enriched eggs for the consumers. It has been shown that egg selenium content can easily be manipulated to give increased levels, especially when organic selenium is included in hen's diet at levels that provide $30.5 \mathrm{mg} \mathrm{kg}^{-1}$ selenium in the feed [143]. Chickens are also a source of meat for the majority of human population. A study was conducted to investigate the effects of SeMet and sodium selenite supplementation on meat quality and antioxidant status in broilers. The results indicated that SeMet supplementation was more effective than sodium selenite supplementation for increasing $\mathrm{Se}$ in serum and tissues, enhancing antioxidant activities and reducing the drip loss of breast muscle [144]. In an experiment, dietary seleniumenriched probiotics (SP) supplementation increased the rate of egg laying, day egg weight, mean egg weight, egg Se content, and egg GSH-Px activity but also decreased the feed:egg ratio and egg cholesterol content. Results suggested that Se contents, GSH-Px activity, and Haugh units (HU) of eggs were affected by the dietary Se level, whereas the egglaying performance and egg cholesterol content were affected by the dietary probiotics [145].

Se-enriched cow milk can be produced by varying dietary Se supplementation in the form of selenized yeast [146]. Dietary supplementation with Se yeast in lactating dairy cows increased Se milk concentrations in Australia [147]. In China, supplementation of diet with Se-enriched yeast was more effective than sodium selenite in producing favorable cow milk with high polyunsaturated fatty acids and $\mathrm{Se}$ concentrations [67]. In a similar study, Holstein cows' diet was supplemented with either Se yeast or selenite. Results showed that Se yeast may be more effective than sodium selenite in improving the antioxidant status and increasing the whole blood and milk Se concentrations of dairy cows [148]. A daily supplementation of 1-6 mg organic selenium to the feed of dairy cows increased the selenium content of milk from $8 \mu \mathrm{g} \mathrm{kg}^{-1}$ to $94 \mu \mathrm{g} \mathrm{kg}^{-1}$ in 8 weeks [96].

Selenium coming from inorganic forms is less efficiently absorbed and incorporated into milk compared with organic sources, probably due to its reduced bioavailability [149]. Supplementing dairy cow diets with organic Se not only increases Se concentration in milk, but also increase its bioavailability [146]. It has been estimated that selenium requirements could be met by the consumption of 2-3 dl selenium-enriched milk until the age of 8 and with 4-6 dl selenium-enriched milk until the age of 20 [96].

\section{Conclusion}

The amounts of Se required for animal and human health is supplied through food crops and forage which is in turn dependent on Se levels in the soil. This means that plant available $S e$ in the soil determines the Se status of animals and humans which could be deficient, adequate or toxic. Recommended daily intake of Se is determined independently by each country and varies with age, sex and other factors. The recommended daily allowance (RDA) may not be adequate because other selenoenzymes have been discovered which require higher Se intake. Selenium requirements for animals and humans can be supplied through diet or supplementation. Selenium supplementation has been used to successfully treat patients with dilated cardiomyopathy, reduce HIV viral loads and has been shown to reduce cancer risk. Although supplements can be used as a remedy for Se deficiency, a well balanced diet with adequate Se can be used to prevent health problems associated with Se deficiency. Even though inorganic Se was approved as feed additives for livestock, Se-Met is the chief nutritional form of Se. Deficiency of Se-Met is often mistaken for Se deficiency because research has shown that Se-Met is more effective than inorganic selenite. Problems associated with the use of inorganic selenite as supplements include less efficient absorption, potential toxicity, low transfer to milk, meat and egg; and inability to build Se reserves in the body because of greater excretion. Food fortified with Se has been shown to be more efficient than supplementation. Fish and meat products contain higher Se than plant products with fish products having the highest Se content. Selenium content of food crops can be increased by agronomic bio-fortification which involves fertilization of soils and enrichment of animal feeds or basal diets. Addition of Se to fertilizers in Finland is an example of successful agronomic bio-fortification which has led to higher Se status in the human population. The fortification of animal feeds or basal diets with Se has also been successfully used to increase Se content of meat, fish, eggs and milk. Selenium content of food crops and forages can also be increased through genetic bio-fortification in which case key genes of Se hyperaccumulators are identified and manipulated to increase Se accumulation in plants. The efficient transfer of $\mathrm{Se}$ in the soil-crop-animal system is important for adequate human nutrition and health.

\section{References}

[1] Saha, U., Fayiga, A., Sonon, L. 2017. Selenium in the SoilPlant Environment: A Review. Int. J. Applied Agric. Sci. 3, (1): 1-18. doi: 10.11648/j.jjaas.20170301.11.

[2] Rayman, M. P. 2000. The importance of selenium to human health. Lancet 356, 233-241.

[3] Benstoem, C., Goetzenich, A., Kraemer, S., Borosch, S., Manzanares, W., Hardy, G., Stoppe, C. 2015. Selenium and its supplementation in cardiovascular disease-what do we know? Nutrients, 7 (5): 3094-3118.

[4] Zhang, Z., Zhang, J., Xiao, J. 2014. Selenoproteins and selenium status in bone physiology and pathology. Biochimica et Biophysica Acta - General Subjects, 1840 (11): 3246-3256. DOI: 10.1016/j.bbagen.2014.08.001. 
[5] Hatfield, D. L., Tsuji, P. A., Carlson, B. A., Gladyshev, V. N. 2014. Selenium and selenocysteine: roles in cancer, health, and development. Trends Biochem. Sci. 39: 112120.doi:10.1016/j.tibs.2013.12.007.

[6] Roman, M., Jitaru, P., and Barbante, C. (2014).Selenium biochemistry and its role for human health. Metallomics 6 , 25-54.doi:10.1039/C3MT00185G.

[7] Riza, M., Mehmood, K. T. 2011. Selenium in human health and disease:A review. JPMI 26: 120-133.

[8] Guo, L., Lang, M., Chandrasekar, R., Liu, G. 2014. Advances in the Study of Genetic Enrichment of Selenium in Plants. Clon Transgen 3:121. doi:10.4172/2168-9849.1000121.

[9] Li, S. J., Li, W., Hu, X., Yang, L. S., Xirao, R. D., 2009. Soil selenium concentration and Kashin-Beck disease prevalence in Tibet, China. Front. Environ. Sci. Eng. China 3: 62-68.

[10] Alfthan, G., Eurola, M., Ekholm, P., Venäläinen, E.-R., Root, T., Korkalainen, K., Hartikainen, H., Salminen, P., Hietaniemi, V., Aspila, P., Aro, A. 2015. Effects of nationwide addition of selenium to fertilizers on foods, and animal and human health in Finland: From deficiency to optimal selenium status of the population. J Trace Elements Medicine Biol. 31: 142-147.

[11] Fordyce, F. (2005). Selenium deficiency and toxicity in the environment. In O. Selinus (Ed.), Essentials of medical geology (pp. 373-415). Elsevier.

[12] Lavu, R. V., Van De Wiele, T., Pratti, V. L., Tack, F., Du Laing, G. 2016. Selenium bioaccessibility in stomach, small intestine and colon: Comparison between pure Se compounds, Se-enriched food crops and food supplements. Food Chem. 197: 382-387. DOI: 10.1016/j.foodchem. 2015.08.001.

[13] Rayman, M. P. 2008. Food-chain selenium and human health: Emphasis on intake. Br.J.Nutr. 100: 254-268.

[14] Johnson, C. C., Fordyce, F. M., Rayman, M. P. 2010. Symposium on Geographical and geological influences on nutrition: factors controlling the distribution of selenium in the environment and their impact on health and nutrition. Proc. Nutr. Soc. 69: 119-132.

[15] Malagoli, M., Schiavon, M., dall' Acqua, S., \& Pilon-Smits, E. A. H. (2015). Effects of selenium biofortification on crop nutritional quality. Frontiers Plant Sci. 6, 280. http://doi.org/10.3389/fpls.2015.00280.

[16] Barclay, M. Allan MacPherson, N. I., Dixon, J. 1995. Selenium content of a range of UK food. J. Food Composition Anal. 8 (4): 307-318. doi:10.1006/jfca.1995.1025.

[17] Funes-Collado, V., Morell-Garcia, A., Rubio, R., LopezSanchez, J. 2013. Study of selenocompounds from seleniumenriched culture of edible Sprouts. Food Chem. 141: 37383743 .

[18] Olson, O. E., Palmer, I. S. 1976. Selenoamino acids in tissues of rats administered inorganic selenium. Metabolism 25: 299306.

[19] Brody, T. 1999. Inorganic nutrients. In: Brody T, editor Nutritional biochemistry. 2nd edn. San Diego: Academic Press, p. 693-878.

[20] Mason, J. B., Garcia M. 1993. Micronutrient deficiency-The global situation. SCN News 9: 11-6.

[21] Kennedy, G., Nantel, G., Shetty, P. 2003. The scourge of "hidden hunger": Global dimensions of micronutrient deficiencies. Food Nutr Agric, 32: 8-16.

[22] Jiang, Y., Zeng, Z., Bu, Y., Ren, C., Li, J., Han, J., Tao, C., Zhang, K., Wang, X., Lu, G., Li, Y., Hu, Y. 2015. Effects of selenium fertilizer on grain yield, Se uptake and distribution in common buckwheat (Fagopyrum esculentum Moench). Plant Soil Environ. 61 (8): 371-377. doi: 10.17221/284/2015-PSE.

[23] Edmondson, A. J., Norman, B. B., Surther, D. 1993. Survey of state veterinarians and state veterinary diagnostic laboratories for selenium deficiency and toxicosis in animals. J. American Veterinary Medicine Association, 202: 865-872.

[24] Qin, H. B., Zhu, J. M., Liang, L., Wang, M. S., Su, H. 2013. The bioavailability of selenium and risk assessment for human selenium poisoning in high-Se areas, China. Environ. Intern., 52: 66-74. DOI: 10.1016/j.envint.2012.12.003.

[25] Dhillon, K., \& Dhillon, S. 2014. Development and mapping of seleniferous soils in northwestern India. Chemosphere99: 5663.

[26] Welch, R. M., Combs Jr, G. F., Duxbury, J. M. 1997. Toward a "Greener" revolution. Issues Sci Technol. 14: 50-8.

[27] Combs Jr, G. F., Welch, R. M., Duxbury, J. M., Uphoff, N. T., Nesheim, M. C. 1996. Food-based approaches to preventing micronutrient malnutrition: An international research agenda. Cornell International Institute for Food, Agriculture, and Development. Ithaca NY: Cornell University.

[28] Schwarz, K., Foltz, C. M. 1957. Selenium as an integral part of factor 3 against dietary necrotic liver degeneration. J. Am. Chem. Soc. 79: 3392-3393.

[29] FDA (U.S. Food and Drug Administration).1974. Title 21, Code of Federal Regulations, Part 573.920. January 9, 1974.

[30] FDA (US Food and Drug Administration). 2004. Title 21. Food and Drugs: Food additives permitted in feed and drinking water of animals. Available online at https://www.accessdata.fda.gov/scripts/cdrh/cfdocs/cfcfr/CFR Search.cfm?CFRPart=573. Accessed February 22, 2017.

[31] Schrauzer, G. N. 2000. Selenomethionine: a review of its nutritional significance, metabolism and toxicity. J. Nutr., 130: $1653-1656$.

[32] Weiss, W. P. 2003. Selenium nutrition of dairy cows: Comparing responses to organic and inorganic selenium forms. Pages 333- 343 in Proc. 19th Alltech Annual Symp. Nutr., Biotechnol. Feed Food Ind. P. T. Lyons and K. A. Jacques, ed. Nottingham University Press, Nottingham, UK.

[33] Spallholz, J. E. 1997. Free radical generation by selenium compounds and their prooxidant toxicity. Biomedicine Environ. Sci. 10, 260-270.

[34] Mahan, D. C. 2001. Selenium and Vitamin E in Swine Nutrition. In: A. J. Lewis and L. L. Southern (eds.), Swine Nutrition, Second Edition, CRC Press, New York. Pp 282314.

[35] Surai, P. F., Fisinin, V. I., Papazyan, T. T. 2008. Selenium deficiency in Europe: causes and consequences. In: P. F. Surai and J. A. Taylor-Pickard (eds.) Current advances in selenium research and applications, pp.13-44. Wageningen Academic Publishers, The Netherlands. 
[36] Eisenberg, S. (2007). Relative stability of selenites and selenates in feed premixes as a function of water activity. J. AOAC Int., 90: 349-353.

[37] Groce, A. W., Miller, E. R., Ullrey, D. R., Ku, P. K., Keahey, K. K., Ellis, D. J. 1973. Selenium requirements in corn-soy diets for growing-finishing swine. J Animal Sci. 37, 948-956.

[38] Suzuki, K. T., and Y. Ogra. 2002. Metabolic pathway for selenium in the body: Speciation by HPLC-ICP MS with enriched Se. Food Addit. Contam. 19: 974-983.

[39] Juniper, D. T., R. H. Phipps, A. K. Jones, and G. Bertin. 2006. Selenium Supplementation of Lactating Dairy Cows: Effect on Selenium Concentration in Blood, Milk, Urine, and Feces. J. Dairy Sci. 89: 3544-3551.

[40] Schrauzer, G. N. 2003. The nutritional significance, metabolism and toxicology of selenomethionine. Adv. Food Nutr. Res., 47:73-112.

[41] Terry, N., Zayed, A. M., de Souza, M. P., Tarun, A. S. 2000. Selenium in higher plants. Ann. Rev. Plant Physiol. Plant Mol. Biol., 51: 401-432.

[42] Whanger, P. D. 2002. Selenocompounds in plants and animals and their biological significance. J. Amer. Col. Nutr., 21: 223 232 .

[43] Schrauzer, G. N., Surai, P. F. 2009. Selenium in human and animal nutrition: Resolved and unresolved issues. A partly historical treatise in commemoration of the fiftieth anniversary of the discovery of the biological essentiality of selenium, dedicated to the memory of Klaus Schwarz (1914-1978) on the occasion of the thirtieth anniversary of his death. Critical Reviews in Biotechnology, 29: 1, 2-9.

[44] Pehrson, B., Ortman, K., Madjid, N., Trafikowska, U. 1999. The influence of dietary selenium as selenium yeast or sodium selenite on the concentration of selenium in the milk of suckler cows and on the selenium status of their calves. J. Anim. Sci. 77: 3371-3376.

[45] Bierla, K., Dernovics, M., Vacchina, V., Szpunar, J., Bertin, G., Lobinski, R. 2008. Determination of selenocysteine and selenomethionine in edible animal tissues by $2 \mathrm{D}$ sizeexclusion reversed-phase HPLC-ICP-MS following carbamidomethylation and proteolytic extraction. Analyt. Bioanalytic. Chem., 390: 1789-1798.

[46] Bertin, G. and Brillard, J. P. 2008. Effect of selenium source and dose on the accumulation and distribution of total selenium and selenized amino acids in the yolk, albumen and whole chicken egg. WPSA J., 64 (Suppl 2): 228.

[47] Blau, M. 1961. Biosynthesis of [7SSe] selenomethionine and [TsSe] selenocystine. Biochim. Biophys. Acta 49, 389.

[48] Schrauzer, G. N. 2006. Selenium yeast: composition, quality, analysis, and safety". Pure Appl Chem. 78: 105-109.

[49] Mahan, D. C. 2005. Organic selenium fed to swine - its potential impact on human health issues. In: Midwest Swine Nutrition Conference. Indianapolis, IN, 2005.

[50] Surai, P. F., Karadas F., Pappas, A., Sparks, N. 2006. Effect of organic selenium in quail diet on its accumulation in tissues and transfer to the progeny. Br Poult Sci. 47: 65-72.

[51] Fisinin, V., Papazyan, T., Surai, P.F. 2009. Producing selenium-enriched eggs and meat to improve the selenium status of the general population". Crit Rev Biotech. 29: 18-28.

[52] Navas-Carretero S, Cuervo, M. Abete, I., Zulet, M., Martinez. J. 2010. Frequent consumption of selenium-enriched chicken meat by adults causes weight loss and maintains their antioxidant status. Biol Trace Elem Res. 143: 8-19.

[53] Spallholz, J.E., Rafferty, A. 1987. In Selenium in Biology and Medicine, Part A, G. F. Combs, J. E. Spallholz, O. A. Levander, J. E. Oldfield (Eds.), pp. 516-529, Van Nostrand Reinhold, New York.

[54] Kim, Y. Y., Mahan, D. C. 2001. Comparative effects of high dietary levels of organic and inorganic selenium on selenium toxicity of growing-finishing pigs. J. Anim. Sci. 79, 942.

[55] Delezie, E., M. Rovers, A. Van der Aa, A. Ruttens, S. Wittocx, and L. Segers. 2014. Comparing responses to different selenium sources and dosages in laying hens. Poultry Sci. 93: 3083-3090.

[56] Yang, G-Q., Zhu, L-Z., Liu, S-J., Gu, L-Z., Qian, P-C., Huang, J-H. and $\mathrm{Lu}, \mathrm{M}-\mathrm{D}$. (1987). Human selenium requirements in China. In: Selenium inBiology and Medicine. (Eds.: Combs, G. F. Jr., Spallholz, J. E., Levander, O. A. and Oldfield, J. E), New York: Van Nostrand Reinhold Company, pp. 589-607.

[57] Aro, A., Kumpalainen, J., Alfthan, G., Voshchenko, A. V. and Ivanov, V.N. (1994). Factors affecting the selenium intake of people in Tranbaikalian Russia. Biol. Trace El. Res., 40:277-285.

[58] Pavlata, L, A. Pechova, and J. Illek. 2000. Direct and indirect assessment of selenium status in cattle. Acta Vet. Brno. 69: 281-287.

[59] Dargatz, D. A., Ross, P. F. 1996. Blood selenium concentrations in cows and heifers on 253 cow-calf operations in 18 states. J. Anim. Sci. 74: 2891-2895.

[60] Villard, D., Arthur, J. R., Gonzalez, J. M., Pallares, F. J. 2002. Selenium status in cattle: Interpretation of laboratory results. Bovine Pract. 36: 73-80.

[61] NRC. 1996. Nutrient Requirements of Beef Cattle. 7th revised edition. National Academy Press. Washington, D. C. 242 p.

[62] Longnecker, M. P., Stram, D. O., Taylor, P. R., Levander, O. A., Howe, M., Veillon, C., McAdam, P. A., Patterson, K. Y., Holden, J. M., Steven Morris, J. 1996. Use of selenium concentration in whole blood, serum, toenails, or urine as a surrogate measure of selenium intake. Epidemiology 7: 384-390.

[63] Ellis, R. G., Herdt, T. H., Stone, H. D. 1997. Physical, hematologic, biochemical and immunologic effect of supranutritional supplementation with dietary selenium in dairy cows. Am. J. Vet. Res. 58: 760-764.

[64] Hall, J. A., Bobe, G., Hunter, J. K., Vorachek, W. R., Stewart, W. C., Vanegas, J. A., Estill, C. T., Mosher, W. D., Pirelli, G. J. 2013. Effect of feeding selenium-fertilized alfalfa hay on performance of weaned beef calves. PLoS ONE 8: e58188.

[65] Chorfi, Y., Girard, V., Fournier, A., Couture, Y. 2011. Effect of subcutaneous selenium injection and supplementary selenium source on blood selenium and glutathione peroxidase in feedlot heifers. Can. Vet. J. 52: 1089-1094.

[66] Mehdi, Y., Clinquart, A., Hornick, J.-L., Cabaraux, J.-F., Istasse, L., Dufrasne, I. 2015. Meat composition and quality of young growing Belgian Blue bulls offered a fattening diet with selenium enriched cereals. Can. J. Anim. Sci. 95: 465-473. 
[67] Ran, L., Wu, X., Shen, X., Zhang, K., Ren, F., Huang, K. 2010. Effects of selenium form on blood and milk selenium concentrations, milk component and milk fatty acid composition in dairy cows. J. Sci. Food Agric. 90: 2214-2219.

[68] Weiss,W. P., Hogan, J. S. 2005. Effect of selenium source on selenium status, neutrophil function, and response to intramammary endotoxin challenge of dairy cows. J. Dairy Sci. 88, 4366-4374.

[69] Würmli, R., Wolffram, S., Stingelin, Y. and Scharrer, E. 1989. Stimulation of mucosal uptake of selenium from selenite by Lcysteine in sheep small intestine. Biol. Trace Elem. Res., $20: 75-85$

[70] Griffiths, N. M., Stewart, R. D. H. and Robinson, M. F. 1976. The metabolism of [75Se] selenomethionine in four women. Br. J. Nutr., 35: 373-382.

[71] Thomson C. D., Stewart R. D. H. 1974. The metabolism of ${ }^{75}$ Se selenite in young women. Br. J. Nutr. 32, 303-323.

[72] Swanson, C. A., Patterson, B. H., Levander, O. A., Veillon, C., Taylor, P. R., Helzlsouer, K., McAdam, P. A. and Zech, L. A. 1991. Human [74Se] selenomethionine metabolism: a kinetic model. Am. J. Clin. Nutr., 54: 917-926.

[73] Daniels, L. A. 1996. Selenium metabolism and bioavailability. Biol. Trace Elem. Res., 54: 185-199.

[74] Wolffram, S. 1999. Absorption and metabolism of selenium: difference between inorganic and organic sources. In: Biotechnology in the feedindustry. Proceedings of Alltech's 15th Annual Symposium (Eds.: Lyons, T. P. and Jacques, K. A.), Nottingham: Nottingham University Press, pp. 547-566.

[75] Flohe, L., Günzler, W. A., Schock, H. H. 1973. Glutathione peroxidase: A selenoenzyme, FEBS Letters, 32, (1):132-134, http://dx.doi.org/10.1016/0014-5793(73)80755-0.

[76] Hatfield, D. L., Tsuji, P. A., Carlson, B. A., Gladyshev, V. N. (2014).Selenium and selenocysteine: roles in cancer, health, and development. Trends Biochem. Sci. 39, 112120.doi:10.1016/j.tibs.2013.12.007.

[77] Rayman, M. P. 2012. Selenium and human health. Lancet 379: $1256-1268$.

[78] Beck, M. A., Handy, J., Levander, O. A. 2004. Host nutritional status: The neglected virulence factor. Trends Microbiol., 12, 417-423.

[79] Jun, E. J., Ye, J. S., Hwang, I. S., Kim, Y. K., Lee, H. 2011. Selenium deficiency contributes to the chronic myocarditis in coxsackievirus-infected mice. Acta Virol.55: 23-29.

[80] Al-Matary, A., Hussain, M., Ali, J. 2013. Selenium: A brief review and a case report of selenium responsive cardiomyopathy. BMC Pediatrics, 13 (1), DOI: 10.1186/14712431-13-39.

[81] Hurwitz, B. E., Klaus, J. R., Llabre, M. M., Gonzalez, A., Lawrence, P. J., Maher, K. J., et al. (2007). Suppression of human immunodeficiency virus type 1 viral load with selenium supplementation: A randomized controlled trial. Archives Internal Medicine, 167: 148-154.

[82] Shor-Posner, G., Lecusay, R., Miguez, M., Moreno-Black, G., Zhang, G., Rodriguez, N., et al. (2003). Psychological burden in the era of HAART: Impact of selenium therapy. International J. Psychiatry Medicine, 33, 55-69.
[83] Pitney, C. L., Royal, M., Klebert, M. 2009. Selenium Supplementation in HIV-Infected Patients: Is There Any Potential Clinical Benefit? Journal of the Association of Nurses in AIDS Care, 20 (4): 326-333. DOI: 10.1016/j.jana.2009.03.006

[84] Schrauzer, G. N., White, D. A., Schneider, C. J. 1977. Cancer mortality correlation studies-III: statistical associations with dietary selenium intakes, Bioinorg. Chem. 7: 23-31.

[85] Clark, L. C., Combs Jr., G. F., Turnbull, B. W. et al., 1996. Effects of selenium supplementation for cancer prevention in patients with carcinoma of the skin. A randomized controlled trial, JAMA 276: 1957-1963.

[86] Allen, N. E., Appleby, P. N., Roddam, A. W. et al., 2008. Plasma selenium concentration and prostate cancer risk: results from the European Prospective Investigation into Cancer and Nutrition (EPIC), Am. J. Clin. Nutr. 88: 15671575 .

[87] Steinbrenner, H., Seis, H. 2009. Protection against reactive oxygen species by selenoproteins. Biochimica et Biophysica Acta 1790: 1478-1485.

[88] Bleys, J., Navas-Acien, A., Guallar, E. 2007. Serum selenium and diabetes in U.S. adults. Diabetes Care, 30 (4): 829-834. DOI: $10.2337 / \mathrm{dc} 06-1726$.

[89] Stranges, S., Marshall, J. R., Natarajan, R., Donahue, R. P., Trevisan, M., Combs, G. F., et al. 2007. Effects of long-term selenium supplementation on the incidence of type 2 diabetes: a randomized trial. Ann Intern Med, 147: 217-23.

[90] Laclaustra, M., Navas-Acien, A., Stranges, S., Ordovas, J. M., Guallar, E. 2009. Serum selenium concentrations and hypertension in the US population. Circulation: Cardiovascular Quality and Outcomes, 2 (4): 369-376. DOI: 10.1161/CIRCOUTCOMES.108. 831552.

[91] Stapleton, S. R. 2000. Selenium: An insulin-mimetic. Cell Mol Life Sci 2000; 57: 1874-9.

[92] Mueller, A. S., Pallauf, J. 2006. Compendium of the antidiabetic effects of supranutritional selenate doses. In vivo and in vitro investigations with type II diabetic $\mathrm{db} / \mathrm{db}$ mice. J Nutr Biochem, 17: 548-60.

[93] Akbaraly, T. N., Arnaud, J., Rayman, M. P., Hininger-Favier, I., Roussel, A. M., Berr, C., et al. 2010. Plasma selenium and risk of dysglycemia in an elderly French population: results from the prospective epidemiology of vascular ageing study. Nutr Metab7: 21.

[94] Navarro-Alarcon, M., Cabrera-Vique, C. 2008. Selenium in food and the human body: A review. Sci Total Environ. 400 (1): $115-141$.

[95] Tinggi, U. 2008. Selenium: Its role as antioxidant in human health. Environ. Health Preventive Medicine, 13 (2): 102108 .

[96] Csapo, J., Hollo, G., Hollo, I., Salamon, S., Toro, S. 2015. Production of selenium-enriched milk and dairy products. Acta Univ. Sapientiae, Alimentaria, 8 (2015) 5-29. DOI: 10.1515/ausal-2015-0001.

[97] Weaver, C. M., Davis, J., Marks, H. S., Sensmeier, R. K. 1988. Selenium content of processed soybeans. J Food Sci. 53: 300301. 
[98] Diaz-Alarcon, J. P., Navarro-Alarcon, M., Lopez, G., de la Serrana, H, Lopez-Martinez, M. C. 1994. Determination of selenium in fresh fish from southeastern Spain for calculation of daily dietary intake. J Agric Food Chem 42: 334-337.

[99] Jaffar, M., Ashraf, M. 1989. Selected trace metal concentrations in different tissues of fish from coastal waters of Pakistan Arabian Sea.. Ind J Mar Sci. 17: 231-234.

[100] Diaz-Alarcon, J. P. 1995. Determination of selenium in food, water and soil cultivation in Motril and relation area with input in the daily intake. Ph.D. Dissertation. Granada: University of Granada, 1995.

[101] Navarro-Alarcón, M., López-Martínez， M. C. 2000. Essentiality of selenium in the human body: Relationship with different diseases. Science of the Total Environment, 249 (13), pp. 347-371. DOI: 10.1016/S0048-9697 (99) 00526-4.

[102] Lyons, G., Stangoulis, J., Graham, R. 2003. Nutriprevention of disease with high-selenium wheat. J Australas Coll Nutr Environ Med. 22: 3-9.

[103] Ventura, M. G., Freitas, M. D., Pacheco, A., Van Meerten, T., Wolterbeek, H. T. 2007. Selenium content in selected Portuguese foodstuffs. Eur Food Res Technol. 224: 395-401.

[104] Navarro-Alarcon M., Cabrera-Vique, C. 2008. Selenium in food and the human body: A review. Sci Total Environ. 400 (1): 115-141.

[105] Sirichakwal, P. P., Puwastein, P., Polngam, J., Kongkachuichai, R. 2005. Selenium content of Thai foods. J Food Compos Anal. 18: 47-59.

[106] Dumont, E., Vanhaecke, F., Cornelis, R. 2006. Selenium speciation from food source to metabolites: A critical review. Anal Bioanal Chem. 385: 1304-23.

[107] Kapolna, E., Fodor, P. 2007. Bioavailability of selenium from selenium-enriched green onions (Allium fistulosum) and chives (Allium schoenoprasum) after 'in vitro' gastrointestinal digestion. Int J Food Sci Nutr. 58: 282-96.

[108] Manjusha, R., Dash, K., Karunasagar, D. 2007. UV-photolysis assisted digestion of food samples for the determination of selenium by electrothermal atomic absorption spectrometry (ETAAS). Food Chem. 105: 26-265.

[109] Pappa, E. C., Pappas, A. C., Surai, P. F., 2006. Selenium content in selected foods from the Greek market and estimation of the daily intake. Sci. Total Environ. 372 (1): 100-108.

[110] McNaughton, S. A., Marks, G. C. 2002.Selenium content of Australian foods: A review of literature values. J Food Compos Anal. 15: 169-82.

[111] Al-Ahmary, K. M. 2009. Selenium content in selected foods from the Saudi Arabia market and estimation of the daily intake, Arabian J. Chem. 2, (2): 95-99.

[112] Thomson, C. D. 2004. Assessment of requirements for selenium and adequacy of selenium status: A review. Eur J Clin Nutr. 58: 391-402.

[113] Oropeza-Moe, M., Wisløff, H., Bernhoft, A. 2015. Selenium deficiency associated porcine and human cardiomyopathies. J. Trace Elements Medicine Biol. 31 (2015) 148-156.

[114] Ralston, N. V. C., Raymond, L. J. 2010. Dietary selenium's protective effects against methylmercury toxicity. Toxicol. 278

\section{(1): 112-123. DOI: $10.1016 /$ j.tox.2010.06.004}

[115] Zhang, Z. W., Shimbo, S., Qu, J. B., Watanabe, T., Nakatsuka, H., Matsuda-Inoguchi, N., Higashikawa, K., Ikeda, M. 2001. Dietary selenium intake of Chinese adult women in the 1990s. Biol. Trace Element Res. 80 (2): 125-138. DOI: 10.1385/BTER: 80: 2: 125 .

[116] Waegeneers, N., Thiry, C., De Temmerman, L., Ruttens, A. 2013. Predicted dietary intake of selenium by the general adult population in Belgium. Food Additives and Contaminants Part A Chemistry, Analysis, Control, Exposure and Risk Assessment, 30 (2): 278-285. DOI: 10.1080/19440049. 2012.7 46474.

[117] Oster, O., Prellwitz, W. 1989. The daily dietary selenium intake of West German adults. Biol Trace Elem Res. 20: 1. doi: 10.1007/BF02919093.

[118] Food and Nutrition Board (FNB). 2000. Dietary Reference Intakes: Vitamin C, Vitamin E, Selenium, and Carotenoids. Institute of Medicine, National Academy Press, Washington, DC.

[119] Levander, O. A., Morris, V. C. 1984. Dietary selenium levels needed to maintain balance in North American adults consuming self-selected diets. Am. J. Clin. Nutr., 39: 809815 .

[120] Han, L., Zhou, S. M. 1994. Selenium supplement in the prevention of pregnancy induced hypertension. Chinese Med. J. (in English), 107: 870-871.

[121] Kumpulainen, J., Salmenpera, L., Siimes, M. A., Koivistoinen, P., Perheentupa, J. 1985. Selenium status of exclusively breast-fed infants as influenced by maternal organic and inorganic selenium supplementation. Am. J. Clin. Nutr., 42: 929-835.

[122] Broadley, M. R., White, P. J., Bryson, R. J., Meacham, M. C., Bowen, H. C., Johnson, S. E., Hawkesford, M. J., McGrath, S. P., Zhao, F. J., Breward, N., Harriman, M., Tucker, M. 2006. Biofortification of UK food crops with selenium. Proceedings of the Nutrition Society, 65 (2): 169-181. DOI: 10.1079/PNS2006490.

[123] Pilon-Smits, E. A. 2014. Engineering plant selenium accumulation: Potential uses and ecological impacts. Eds. Banuelos, Lin and Yin. In Selenium in the environment and human health. Taylor and Francis group, London, pp $217-$ 218 .

[124] Lyons, G. H., Stangoulis, J. C., Graham, R. D. 2004. Exploiting micronutrient interaction to optimize biofortification programs: The case for inclusion of selenium and iodine in the HarvestPlus program. Nutrition Rev. 62: 247-252.

[125] Li, Y., Li Y., Chen, D. 2003. Biological Functions of Selenium and the Mechanism of Selenium Enrichment in Plant. J. Hubei Agric. College 23: 476-480.

[126] LeDuc, D. L., AbdelSamie, M., Montes-Bayón, M., Wu, C. P., Reisinger, S. J., and Terry, N. 2006. Overexpressing both ATP sulfurylase and selenocysteine methyltransferase enhances selenium phytoremediation traits in Indian mustard. Environ. Pollut. 44: 70-76. doi: 10.1016/j.envpol.2006.01.008.

[127] Seppanen, M., Kontturi, J., Hartikainen, H. 2010. Biofortification of food chain with selenium. NJF report 6(2): 6-9. 
[128] Pilon-Smits, E. A. H., Hwang, S. B., Lytle, C. M., Zhu, Y. L., Tai, J. C., Bravo, R. C., et al. 1999. Overexpression of ATP sulfurylase in Brassica juncea leads to increased selenate uptake, reduction and tolerance. Plant Physiol. 119: 123-132. doi: $10.1104 /$ pp.119.1.123.

[129] Ellis, D. R., Sors, T. G., Brunk, D. G., Albrecht, C., Orser, C., Lahner, B., et al. 2004. Production of Se-methylselenocysteine in transgenic plants expressing selenocysteine methyltransferase. BMC Plant Biol. 4:1-11. doi: 10.1186/1471- 2229-4-1.

[130] Lyi SM, Heller LI, Rutzke M, Welch RM, Kochian LV, et al. 2005. Molecular and biochemical characterization of the Selenocysteine Se-Methyltransferase gene and SeMethylselenocysteine synthesis in broccoli. Plant Physiol. 138: 409-420.

[131] Bañuelos, G., Terry, N., Leduc, D. L., Pilon-Smits, E. A., Mackey, B. 2005. Field trial of transgenic Indian mustard plants shows enhanced phytoremediation of seleniumcontaminated sediment. Environ Sci Technol 39: 1771-1777.

[132] Van Huysen, T., Abdel-Ghany, S., Hale, K. L., LeDuc, D., Terry, N., et al. 2003. Overexpression of cystathioninegamma-synthase enhances selenium volatilization in Brassica juncea. Planta 218: 71-78.

[133] Ip, C., Birringer, M., Block, E., Kotrebai, M., Tyson, J., Uden, P. C., Lisk, D. 2000. Chemical speciation influences comparative activity of seleniumenriched garlic and yeast in mammary cancer prevention. J. Agric. Food. Chem., 48: 2062-2070.

[134] Rahman, M. M., Erskine, W., Materne, M. A., McMurray, L. M., Thavarajah, P., Thavarajah, D., Siddique, K. H. M. 2015. Enhancing selenium concentration in lentil (Lens culinaris subsp. culinaris) through foliar application. J. Agric. Sci. 153 (4): 656-665. DOI: 10.1017/S0021859614000495.

[135] Wu, J., Salisbury, C., Graham, R., Lyons, G., Fenech, M. 2009. Increased consumption of wheat biofortified with selenium does not modify biomarkers of cancer risk, oxidative stress, or immune function in healthy Australian males. Environmental and Molecular Mutagenesis, 50 (6): 489-501. DOI: $10.1002 / \mathrm{em} .20490$.

[136] Djujić, I. S., Jozanov-Stankov, O. N., Milovac, M. Janković, V., Djermanović, V. 2000. Bioavailability and possible benefits of wheat intake naturally enriched with selenium and its products. Biol Trace Elem Res (2000) 77 (3): 273-285. doi: 10.1385/BTER:77: 3: 273.

[137] Spadoni, M., Voltaggio, M., Carcea, M., Coni, E., Raggi, A., Cubadda, F. 2007. Bioaccessible selenium in Italian agricultural soils: Comparison of the biogeochemical approach with a regression model based on geochemical and pedoclimatic variables. Sci. Total Environ. 376: 160-177.

[138] Giacosa, A., Faliva, M. A., Perna, S., Minoia, C., Ronchi, A., Rondanelli, M. 2014. Selenium Fortification of an Italian Rice
Cultivar via Foliar Fertilization with Sodium Selenate and Its Effects on Human Serum Selenium Levels and on Erythrocyte Glutathione Peroxidase Activity. Nutrients2014, 6, 12511261; doi:10.3390/nu6031251.

[139] Durán, P., Acuña, J. J., Gianfreda, L., Azcón, R., FunesCollado, V., Mora, M. L. 2015. Endophytic selenobacteria as new inocula for selenium biofortification. Applied Soil Ecology, 96: 319-326. DOI: 10.1016/j.apsoil.2015.08.016.

[140] Ceballos, A., Sánchez, J., Stryhn, H., Montgomery, J. B., Barkema, H.W., Wichtel, J.J. 2009. Meta-analysis of the effect of oral selenium supplementation on milk selenium concentration in cattle. J. Dairy Sci. 92:324-342.

[141] Yang, H., Jia, X. 2014. Safety evaluation of Semethylselenocysteine as nutritional selenium supplement: Acute toxicity, genotoxicity and subchronic toxicity. Regulatory Toxicol. Pharmacol. 70 (3): 720-727. DOI: 10.1016/j.yrtph.2014.10.014.

[142] Bennett, D. C., Cheng, K. M. 2010. Selenium enrichment of table eggs. Poultry Sci. 89 (10): 2166-2172. DOI: 10.3382/ps.2009-00571.

[143] Fisinin, V. I., Papazyan, T. T., Surai, P. F. 2009. Producing selenium-enriched eggs and meat to improve the selenium status of the general population. Critical Rev. Biotechnol. 29 (1): 18-28. DOI: 10.1080/07388550802658030.

[144] Wang, Y. X., Zhan, X. A., Yuan, D., Zhang, X. W., Wu, R. J. 2011. Effects of selenomethionine and sodium selenite supplementation on meat quality, selenium distribution and antioxidant status in broilers. Czech J. Anim. Sci., 56, 2011 (7): 305-313.

[145] Pan, C., Zhao, Y., Liao, S.F., Chen, F., Qin, S., Wu, X., Zhou, H., Huang, K. 2011. Effect of selenium-enriched probiotics on laying performance, egg quality, egg selenium content, and egg glutathione peroxidase activity. J. Agric. Food Chem. 59 (21): 11424-11431. DOI: 10.1021/jf202014k.

[146] Muñiz-Naveiro, Ó., R. Domínguez-González, A. BermejoBarrera, P. BermejoBarrera, J. A. Cocho, and J. M. Fraga. 2006. Study of the bioavailability of selenium in cows' milk after a supplementation of cow feed with different forms of selenium. Anal. Bioanal. Chem. 385: 189-196.

[147] Stockdale, C. R., Gill, H. S. 2011. Effect of duration and level of supplementation of diets of lactating dairy cows with selenized yeast on selenium concentrations in milk and blood after the withdrawal of supplementation. J. Dairy Sci. 94 (5): 2351-2359. DOI: 10.3168/jds.2010-3781.

[148] Gong, J., Ni, L., Wang, D., Shi, B., Yan, S. 2014.Effect of dietary organic selenium on milk selenium concentration and antioxidant and immune status in midlactation dairy cows. Livestock science 170: 84-90. http://dx.doi.org/10.1016/j.livsci.2014.10.003.

[149] Conrad, H. R., Moxon, A. L. 1979. Transfer of dietary selenium to milk. J. Dairy Sci. 62: 404-411. 